\title{
Influence of cooling rate and cerium addition on rapidly solidified Al-TM alloys
}

\author{
A. Michalcová ${ }^{1 *}$, D. Vojtěch ${ }^{1}$, G. Schumacher ${ }^{2}$, P. Novák ${ }^{1}$, M. Klementová ${ }^{3}, J_{\text {S. Serák }}^{1}$, \\ M. Mudrováa ${ }^{4}$ J. Valdaufová ${ }^{4}$ \\ ${ }^{1}$ Institute of Chemical Technology, Prague, Department of Metals and Corrosion Engineering, \\ Technická 5, 16628 Prague, Czech Republic \\ ${ }^{2}$ Helmholtz-Zentrum Berlin für Materialien und Energie GmbH, Glienicker Straße 100, D-14109 Berlin, Germany \\ ${ }^{3}$ Institute of Inorganic Chemistry of the Academy of Sciences, p.r.i., Husinec- ̌rež 1001, 25068 Rež, Czech Republic \\ ${ }^{4}$ Institute of Chemical Technology, Prague, Department of Computing and Control Engineering,
} Technická 5, 16628 Prague, Czech Republic

Received 28 May 2009, received in revised form 27 October 2009, accepted 27 October 2009

\begin{abstract}
Rapidly solidified alloys, based on an aluminium-transition metal (TM) system, are promising structural materials. They show good mechanical properties and excellent thermal stability, which is caused by the very fine nanostructure of these materials and by the presence of nonequilibrium intermetallic phases. Influence of the cooling rate and Ce addition on properties of Al-5.5Ce-3Fe-1.5Ti alloy that was prepared by the melt spinning method was studied in this work. It was shown that formation of the quasicrystalline phase depends on the cooling rate during melt spinning. The addition of a few weight percents of Ce modifies phase composition of the alloy and stabilizes quasicrystals at elevated temperatures. However, the influence of Ce addition on hardness was not observed.
\end{abstract}

K e y w ords: rapid solidification (A), Al-TM (A), microstructure (B), aluminium (B)

\section{Introduction}

Aluminium alloys are widely used in automotive and aerospace industry due to their superior strength to weight ratio. Unfortunately, common aluminium alloys can be utilized only up to $250^{\circ} \mathrm{C}$. One of possible methods for preparation of Al-based alloys with improved thermal stability is an addition of elements with low diffusivity in $\mathrm{Al}$ matrix, especially transition metals (TM) in amounts of several weight percents. Unfortunately, these elements have very limited solubility in solid aluminium. Manufacturing of Al-TM alloys can successfully solve this problem by rapid solidification. The rapid solidification causes an increase of the solubility of alloying elements, a refinement of the microstructure, and improves material homogeneity.

At the present time, the most common methods of rapid solidification are: melt atomisation by inert gas, melt spinning and thin surface layer melting. None of these methods produce bulky materials. So the production of TM-rich Al-based alloys generally includes two steps: 1 . powder preparation; 2. powder compaction mostly by hot extrusion. Actually powder is prepared only by atomisation. Melt spinning produces thin ribbons, which should be cryogenic crushed before hot extrusion.

Rapidly solidified Al-based alloys with transition metals (TM) are promising materials for structural applications. Special attention has been devoted to Al-based alloys with high $\mathrm{Al}$ contents (above 80 at.\%) due to their high strength, good thermal stability and low density. Generally, these alloys are divided into the following three groups, according to their mechanical properties [1]: a) high-strength alloys based on Al-RE (RE - rare earth metals), b) high ductility Al-TM alloys and c) thermally stable Al-TM alloys. The most often used alloying elements, in the third group

*Corresponding author: tel.: 00420220444055; e-mail address: michalca@vscht.cz 
of alloys, are transition metals with low diffusivity in $\mathrm{Al}$ matrix, i.e. $\mathrm{Cr}, \mathrm{Fe}$ and $\mathrm{Ti}$. A typical alloy from this group is $\mathrm{Al}-2.5 \mathrm{Cr}-3 \mathrm{Fe}-2.5 \mathrm{Ti}[2,3]$. It was shown that the ability of TMs to thermally stabilize the alloys depends on their solid solubilities in $\mathrm{Al}$ matrix [4]. Maximum solubility of $\mathrm{Fe}$ is very low (0.06 wt.\% [5]), but solubilities of $\mathrm{Cr}$ and $\mathrm{Ti}$ are significantly higher (0.67 wt.\% and 1.24 wt.\% [5], respectively). Considering only these values, such high contents of $\mathrm{Cr}$ and $\mathrm{Ti}$ would not be suitable for thermal stabilization. Nevertheless, the exact roles of various TMs on complex properties of rapidly solidified Al-based alloys have not yet been explained [6].

Our previous research [7] demonstrated that the Al-5.7Cr-2.5Fe-1.3Ti alloy prepared by gas atomisation and subsequent hot extrusion exhibited excellent mechanical properties even after long time annealing at $400^{\circ} \mathrm{C}$. This is the reason why we selected an alloy with a composition of $\mathrm{Al}-5.5 \mathrm{Cr}-3 \mathrm{Fe}-1.5 \mathrm{Ti}$ in this study. This alloy contains a slightly higher Fe content than the previous one. Zhang et al. have shown that $\mathrm{Al}-\mathrm{Fe}$ interaction is very strong and that it leads to the formation of Al-Fe quasicrystals [4]. The presence of quasicrystalline phases retards $\mathrm{Al}$ grain growth at elevated temperatures [8]. Because of the importance of quasicrystals in Al-TM alloys, the influence of the cooling rate on phase composition of $\mathrm{Al}-5.5 \mathrm{Cr}-$ $-3 \mathrm{Fe}-1.5 \mathrm{Ti}$ alloy (prepared by melt spinning) was investigated in this work. The purpose is to determine a minimum quenching rate, which still leads to the formation of quasicrystals.

It was reported that additions of small amounts of Ce (few at.\%) to Al-TM alloys increase the quenching effect and support the formation of a finely mixed structure of quasicrystals and fcc-Al $[9,10]$. This is in agreement with the empirical rules for the prediction of the glass forming ability (GFA) of systems. GFA tends to increase as more components with different atomic radii are added to an alloy. The addition of Ce can support the GFA because of its large atomic radius in comparison with $\mathrm{Al}$. Furthermore, there is a strong negative mixing enthalpy between $\mathrm{Al}$ and $\mathrm{Ce}$. It has also been suggested that another role of $\mathrm{Ce}$ is to enhance the icosahedral order [4].

Although the TMs show a considerable variability in their behaviour in rapidly solidified Al-alloys, roles of the various REs are similar. In order to simplify experimental material, Ce alone was added to a rapidly solidified Al-TM alloy in this study. For potential future applications it would be useful to replace Ce by mischmetal, which is an alloy of $\mathrm{Ce}, \mathrm{La}, \mathrm{Nd}$, and Pr. It would lead to an increase in GFA because of a high number of elements in mischmetal [11], and to a decrease in the cost of the final material because mischmetal is a raw material for Ce production.

\section{Experimental}

Alloys with a composition of Al-5.5Cr-3Fe-1.5Ti$x$ Ce $(x=0,1.5,3$; all concentrations are in wt. $\%$, unless otherwise stated) were studied. Ingots of the alloys were prepared by melting of the appropriate amounts of master alloys and pure metals $(\mathrm{Al}-11 \mathrm{Cr}$, $\mathrm{Al}-4 \mathrm{Ti}, \mathrm{Al}, \mathrm{Fe}$, and $\mathrm{Ce}$ ) in a vacuum induction furnace. Consequently, rapidly solidified ribbons were prepared by melt spinning. Cooling wheel velocities were 1000 rpm, $1800 \mathrm{rpm}$ and $2500 \mathrm{rpm}$, which corresponded to circumferential speeds of $17 \mathrm{~m} \mathrm{~s}^{-1}, 28 \mathrm{~m} \mathrm{~s}^{-1}$ and $40 \mathrm{~m} \mathrm{~s}^{-1}$, respectively. Thickness of rapidly solidified ribbons is strongly dependent on cooling wheel velocity. In this case the thickness was between $0.05 \mathrm{~mm}$ and $0.2 \mathrm{~mm}$. It is assumed that the higher the speed, the higher the cooling rate of a ribbon. Melt spinning procedures were performed both in air and under argon, which prevents oxidation, and which may produce higher cooling rates.

The microstructure of cross-sectioned ribbons was examined using a scanning electron microscope (SEM) Hitachi S $4700(30 \mathrm{kV})$. Phase composition of materials was determined by X-ray diffraction (XRD) (PAN analytical X'Pert PRO + High Score Plus, $\mathrm{Cu}$ anode). DSC analysis (131 Setaram, heating rate of 5 $\mathrm{K} \min ^{-1}$ ) was performed to detect solid state phase transformations. Thin foils for the transmission electron microscopy (TEM) were prepared by electropolishing in a mixture of $\mathrm{C}_{2} \mathrm{H}_{5} \mathrm{OH}: \mathrm{HNO}_{3}$ equal to $3: 1$ at $10 \mathrm{~V}$ and $-20^{\circ} \mathrm{C}$. Intermetallic phases were extracted from rapidly solidified ribbons by selective dissolving of $\mathrm{Al}$ in a solution of $250 \mathrm{~g}$ methanol, $25 \mathrm{~g}$ tartaric acid and $10 \mathrm{~g}$ iodine [12]. Thin foils and intermetallic phases were examined by using a transmission electron microscope Jeol 3010 (accelerating voltage $300 \mathrm{kV}, \mathrm{LaB}_{6}$ ). The structural investigation was completed by EDS (Oxford Instruments) measurements. Vickers hardness HV 0.005 was measured on the cross sectioned ribbons using Neophot 2 light microscope equipped by Hannemann microhardness tester.

Long-term annealing of alloys was carried out in an electric resistance furnace. Selected samples were annealed for $100 \mathrm{~h}$ at $400^{\circ} \mathrm{C}$ to determine the thermal stability of materials.

Image analysis of cross-sectioned rapidly solidified ribbons was carried out using the Matlab analytical system. SEM micrographs of the ribbons were divided into three separated areas: 1 . an ultra rapidly quenched area, with no visible structure, which was formed in the vicinity of the cooling wheel; 2. a slowly quenched area located on the opposite side of the ribbon; and 3. a transition area. Artificial neural networks based on space-domain features were used for the accurate dividing. 

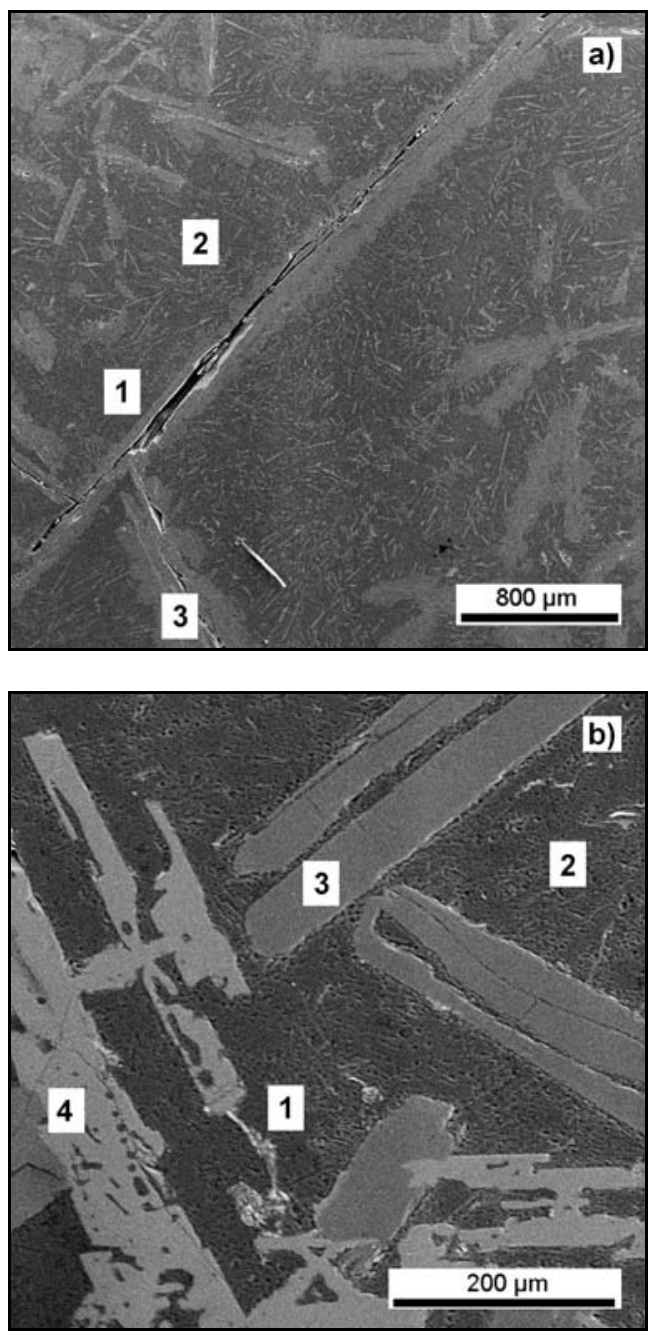

Fig. 1. SEM micrograph: a) Al-5.5Cr-3Fe-1.5Ti cast alloy. Material consists of fcc-Al matrix and intermetallics $\mathrm{Al}_{13} \mathrm{Cr}_{2}$ (large) and $\mathrm{Al}_{13} \mathrm{Fe}_{4}$ (needle-like). EDS chemical analysis of marked points is given in Table $1 \mathrm{a}$; b) Al-5.5Cr$3 \mathrm{Fe}-1.5 \mathrm{Ti}-3 \mathrm{Ce}$ cast alloy. Material consists of fcc-Al matrix and intermetallics $\mathrm{Al}_{13} \mathrm{Cr}_{2}$ (large dark), $\mathrm{Al}_{20} \mathrm{CeCr}_{2}$ (large light) and $\mathrm{Al}_{13} \mathrm{Fe}_{4}$ (needle-like). EDS chemical analysis of marked points is given in Table $1 \mathrm{~b}$.

\section{Results and discussion}

As-cast alloys are characterized by a heterogeneous structure, as illustrated in Figs. 1a and 1b. According to elemental mapping, point chemical analyses given in Tables $1 \mathrm{a}$ and $1 \mathrm{~b}$ and XRD, materials consist of following phases: fcc- $\mathrm{Al}$ (matrix), $\mathrm{Al}_{13} \mathrm{Fe}_{4}$ (fine needle-like phases in matrix), $\mathrm{Al}_{13} \mathrm{Cr}_{2}$ (dark phases), $\mathrm{AlCrFe}_{2}$ (surrounding $\mathrm{Al}_{13} \mathrm{Cr}_{2}$ phases), and $\mathrm{Al}_{20} \mathrm{CeCr}_{2}$ (light phases) in alloys containing Ce. Composition of the $\mathrm{Al}_{13} \mathrm{Fe}_{4}$ phase in Tables $1 \mathrm{a}$ and $1 \mathrm{~b}$ does not correspond exactly to the chemical formula, because the analysis of small particles is affected by surrounding $\mathrm{Al}$ matrix. For the same reason, the $\mathrm{AlCrFe}_{2}$ phase

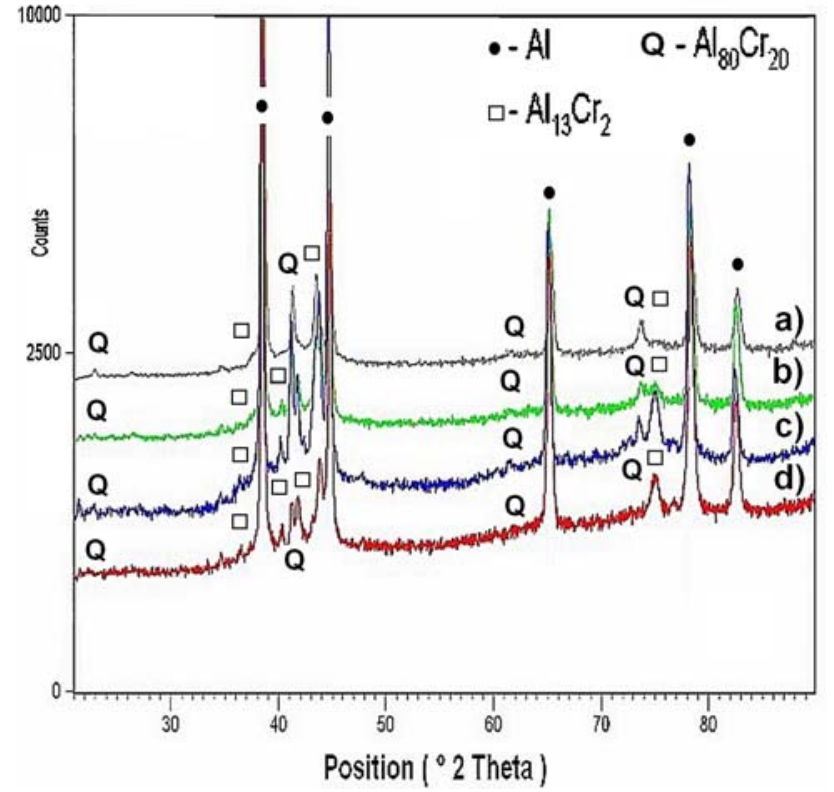

Fig. 2. XRD patterns of Al-5.5Cr-3Fe-1.5Ti alloy prepared at different cooling rates and atmospheres: a) $16 \mathrm{~m} \mathrm{~s}^{-1}$ in air, b) $28 \mathrm{~m} \mathrm{~s}^{-1}$ in air, c) $16 \mathrm{~m} \mathrm{~s}^{-1}$ in Ar, d) $40 \mathrm{~m} \mathrm{~s}^{-1}$ in Ar.

Table 1a. Chemical and phase composition of as-cast alloy Al-5.5Cr-3Fe-1.5Ti

\begin{tabular}{ccrccc}
\hline & \multicolumn{4}{c}{ Chemical composition (at.\%) } & \\
\cline { 2 - 5 } $\begin{array}{c}\text { Point } \\
\text { number }\end{array}$ & $\mathrm{Al}$ & $\mathrm{Cr}$ & $\mathrm{Fe}$ & $\mathrm{Ti}$ & \\
\hline 1 & 99.7 & 0.1 & 0.1 & 0.1 & fcc-Al \\
2 & 99.7 & 0.1 & 0.1 & 0.1 & $\mathrm{Al}_{13} \mathrm{Fe}_{4}$ \\
3 & 83.1 & 12.8 & 3.3 & 0.8 & $\mathrm{Al}_{13} \mathrm{Cr}_{2}$ \\
\hline
\end{tabular}

Table 1b. Chemical and phase composition of as-cast alloy $\mathrm{Al}-5.5 \mathrm{Cr}-3 \mathrm{Fe}-1.5 \mathrm{Ti}-3 \mathrm{Ce}$

\begin{tabular}{ccrcccc}
\hline \multirow{2}{*}{$\begin{array}{c}\text { Point } \\
\text { number }\end{array}$} & \multicolumn{4}{c}{ Chemical composition (at.\%) } & \multirow{2}{*}{ Phase } \\
\cline { 2 - 6 } & $\mathrm{Al}$ & $\mathrm{Cr}$ & $\mathrm{Fe}$ & $\mathrm{Ti}$ & $\mathrm{Ce}$ & \\
\hline 1 & 99.3 & 0.3 & 0.2 & 0.1 & 0.1 & fcc-Al \\
2 & 99.2 & 0.2 & 0.2 & 0.2 & 0.2 & $\mathrm{Al}_{13} \mathrm{Fe}_{4}$ \\
3 & 79.9 & 15.4 & 4.3 & 0.3 & 0.1 & $\mathrm{Al}_{13} \mathrm{Cr}_{2}$ \\
4 & 81.0 & 10.1 & 0.1 & 3.4 & 5.4 & $\mathrm{Al}_{20} \mathrm{CeCr}_{2}$ \\
\hline
\end{tabular}

is not mentioned in Tables $1 \mathrm{a}$ and $1 \mathrm{~b}$. Thin layers of $\mathrm{AlCrFe}{ }_{2}$ phase cannot be distinguished from $\mathrm{Al}_{13} \mathrm{Cr}_{2}$ by EDS analysis, but XRD and elemental mapping proved them. The map of Fe distribution showed the presence of $\mathrm{Fe}$ in fine needle-like phases and in thin rings surrounding the $\mathrm{Al}_{13} \mathrm{Cr}_{2}$ phases. In the matrix 


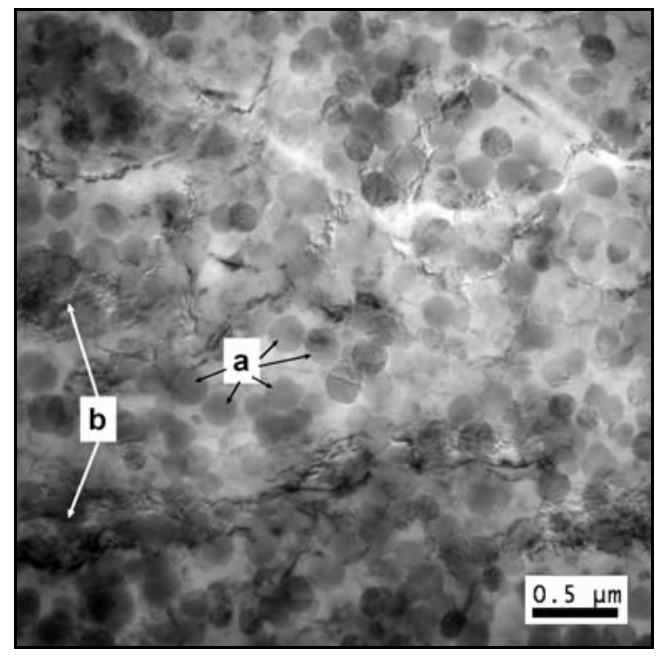

Fig. 3. TEM micrograph of Al-5.5Cr-3Fe-1.5Ti alloy prepared at $40 \mathrm{~m} \mathrm{~s}^{-1}$ in Ar atmosphere. Some examples of quasicrystals are marked by arrows a and cumulated defects by arrows b.

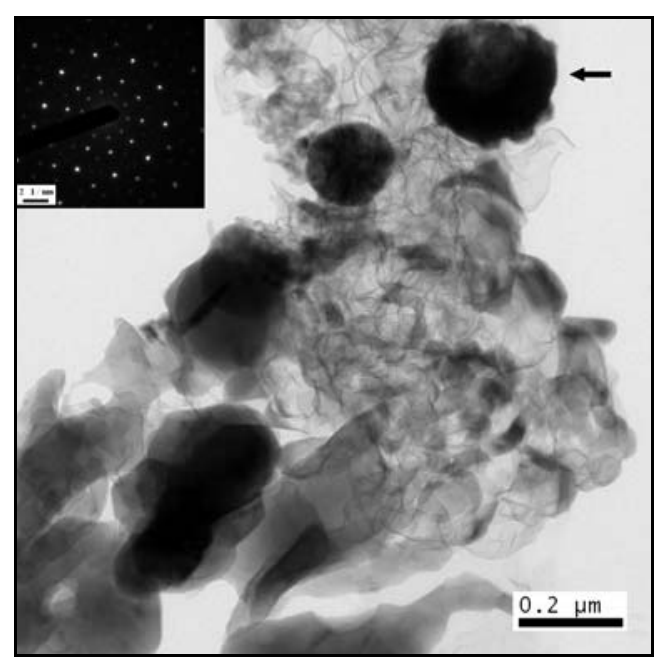

Fig. 4. TEM micrograph of quasicrystalline phase (arrowed) from $\mathrm{Al}-5.5 \mathrm{Cr}-3 \mathrm{Fe}-1.5 \mathrm{Ti}$ sample prepared at $17 \mathrm{~m} \mathrm{~s}^{-1}$ in Ar atmosphere. The inset shows the corresponding electron diffraction pattern with typical decagonal symmetry.

and in the volume of $\mathrm{Al}_{13} \mathrm{Cr}_{2}$, the Fe content was negligible.

Phase composition of the rapidly solidified Al$-5.5 \mathrm{Cr}-3 \mathrm{Fe}-1.5 \mathrm{Ti}$ alloy varies with the cooling rate and surrounding atmosphere, as is shown in Fig. 2. All materials are composed of fcc- $\mathrm{Al}$ and minor phases. In the sample cooled at a wheel rate of $17 \mathrm{~m} \mathrm{~s}^{-1}$ in air there is only the equilibrium $\mathrm{Al}_{13} \mathrm{Cr}_{2}$ phase, while a metastable decagonal phase $\mathrm{Al}_{80} \mathrm{Cr}_{20}$ is observed in the sample cooled at $40 \mathrm{~m} \mathrm{~s}^{-1}$ under argon. In the sample cooled at a wheel rate of $28 \mathrm{~m} \mathrm{~s}^{-1}$

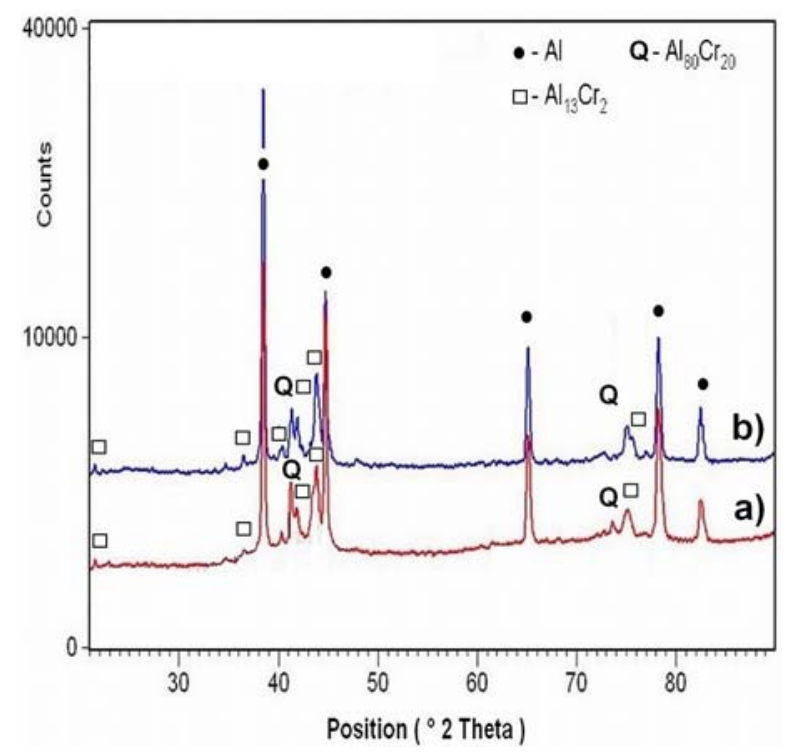

Fig. 5. XRD patterns of Al-5.5Cr-3Fe-1.5Ti ribbons prepared at $28 \mathrm{~m} \mathrm{~s}^{-1}$ : a) rapidly solidified, b) annealed for $100 \mathrm{~h}$ at $400^{\circ} \mathrm{C}$.

in air and $17 \mathrm{~m} \mathrm{~s}^{-1}$ under argon, a mixture of these two phases is formed. Icosahedral coordination is the closest possible coordination. This is the reason why in some melted alloys, which tend to form quasicrystals (such as Al-Fe [4]), there are some quasicrystalline clusters. Sufficiently high cooling rates do not allow the rearrangement of clusters from the melt to some common crystalline structures, resulting in the presence of quasicrystals in rapidly solidified alloys. The presence of quasicrystals was proved by TEM observation of metal foils and extracted intermetallic phases. In a TEM micrograph of the thin foil, shown in Fig. 3, there are uniformly distributed spherical quasicrystals (dark) in the $\mathrm{Al}$ matrix (light). Beside quasicrystals, areas of cumulated defects are observed in Fig. 3. The material structure is too complicated for observing single quasicrystals, so that the $\mathrm{Al}$ matrix was removed by selective dissolution. Quasicrystal extracted from the Al-5.5Cr-3Fe- $1.5 \mathrm{Ti}$ alloy prepared at $17 \mathrm{~m} \mathrm{~s}^{-1}$ under argon is shown in Fig. 4. Quasicrystals exhibit a spherical shape $[1,13]$ and their selected area electron diffraction patterns (SAED) have decagonal symmetry. The composition of the particle is 84.11 at.\% $\mathrm{Al}, 0.76$ at.\% Ti, 7.61 at.\% $\mathrm{Cr}$ and 7.53 at.\% Fe. This shows that Fe atoms having a similar atomic radius substitute a part of the $\mathrm{Cr}$ atoms in the $\mathrm{Al}_{80} \mathrm{Cr}_{20}$ phase. Atomic radii of the elements present in the studied alloy are following [14]: $125 \mathrm{pm}$ for $\mathrm{Al}, 140 \mathrm{pm}$ for $\mathrm{Cr}, \mathrm{Fe}$ and $\mathrm{Ti}$ and $185 \mathrm{pm}$ for Ce.

As shown in Fig. 5, phase composition of the $\mathrm{Al}-5.5 \mathrm{Cr}-3 \mathrm{Fe}-1.5 \mathrm{Ti}$ alloy changes during annealing at $400^{\circ} \mathrm{C} / 100 \mathrm{~h}$. The most probable explanation is that 


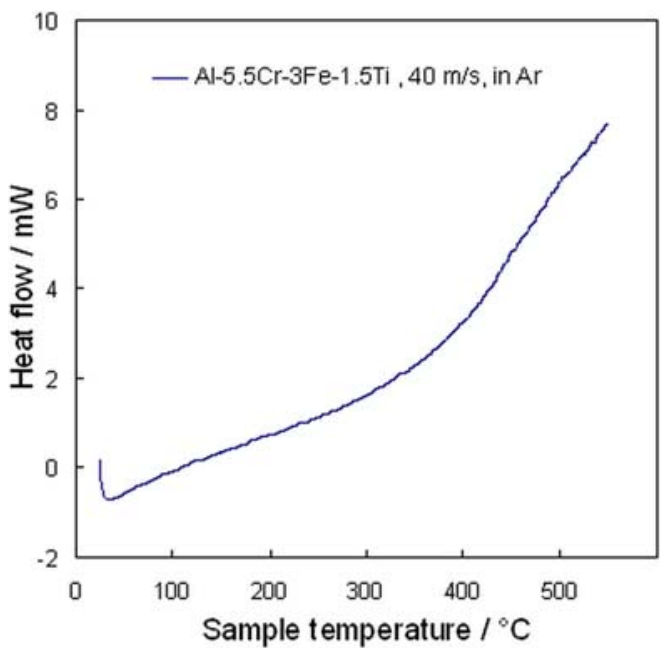

Fig. 6. DCS curve of Al-5.5Cr-3Fe-1.5Ti alloy prepared at $40 \mathrm{~m} \mathrm{~s}^{-1}$, heating rate of $5 \mathrm{~K} \mathrm{~s}^{-1}$.

Ta b l e 2. Assessed Arrhenius parameters for impurity diffusion coefficients in fcc $\mathrm{Al}^{*}$

\begin{tabular}{lccc}
\hline Diffuser & $D_{0}\left(\mathrm{~m}^{2} \mathrm{~s}^{-1}\right)$ & $Q\left(\mathrm{~kJ} \mathrm{~mol}^{-1}\right)$ & Reference \\
\hline $\mathrm{Cr}$ & $6.75 \times 10^{-1}$ & 261.9 & {$[15]$} \\
$\mathrm{Fe}$ & $3.62 \times 10^{-1}$ & 214.0 & {$[15]$} \\
$\mathrm{Ti}$ & $1.12 \times 10^{-1}$ & 260.0 & {$[15]$} \\
$\mathrm{Ce}$ & $4.00 \times 10^{-5}$ & 130.2 & {$[16]$} \\
\hline
\end{tabular}

*Arrhenius equation for diffusion coefficient is $D=D_{0}$ $\exp [-Q /(R T)]$, where $D_{0}$ is denoted as pre-exponential factor and $Q$ as activation energy. $R$ is the gas constant and $T$ the absolute temperature

quasicrystals transform during the thermal treatment to stable phases, in this case $\mathrm{Al}_{13} \mathrm{Cr}_{2}$. A DSC curve of the sample prepared at $40 \mathrm{~m} \mathrm{~s}^{-1}$ is given in Fig. 6. Although the XRD patterns of initial and annealed material differ, there is neither an exothermic nor endothermic reaction on the DSC curve. It is believed that it is caused by a low rate of quasicrystals transformation, suggesting a high structural stability of the alloy. Perhaps, a significantly slower heating rate should be applied to detect this reaction, because all of the alloying elements have very low diffusion coefficients in aluminium matrix, as it is shown in Table 2 .

In Figs. $7 \mathrm{a}-\mathrm{c}$, there are SEM micrographs of alloys with different content of Ce. All ribbons have structure gradients resulting from variations in cooling rates. With increasing the Ce content the structure becomes finer and the homogeneous ultra rapidly quenched area extends from about 7 to $15 \mu \mathrm{m}$, see Table 3 for details. This is in agreement with theoretical expectations about increasing the GFA with Ce addition. Ce increases the number of elements in alloys, Ce and
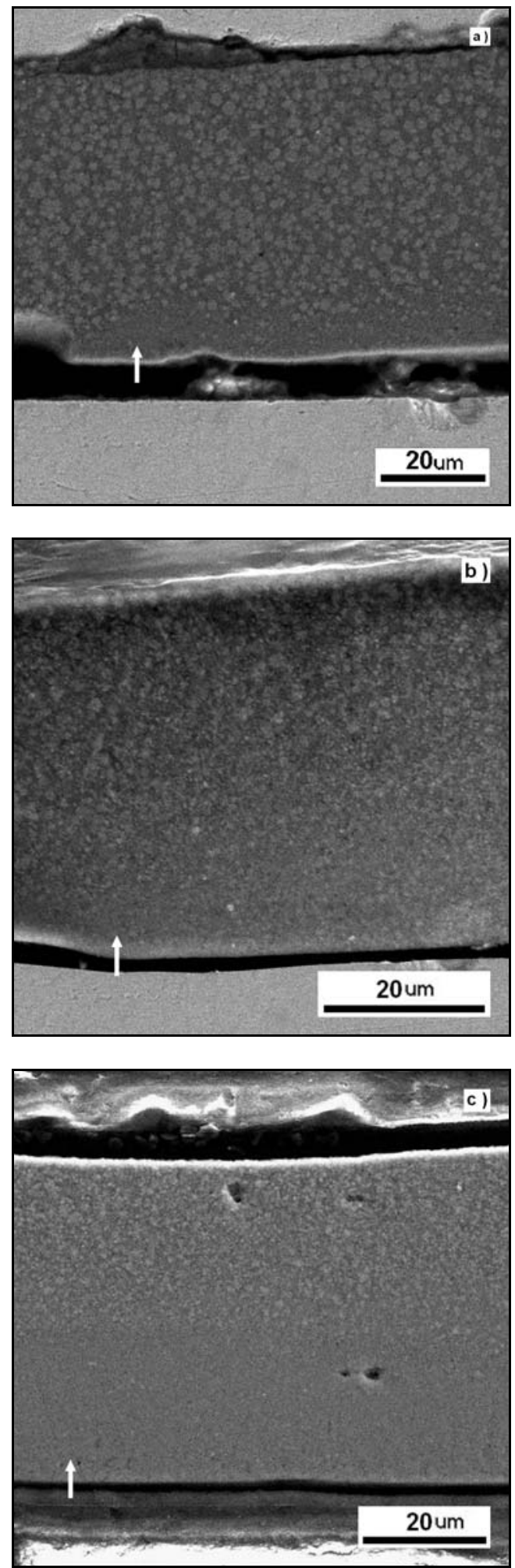

Fig. 7. SEM micrographs: a) rapidly solidified ribbon cross section of Al-5.5Cr-3Fe-1.5Ti alloy prepared at $28 \mathrm{~m} \mathrm{~s}^{-1}$, the wheel side is marked by arrow; b) rapidly solidified ribbon cross-section of $\mathrm{Al}-5.5 \mathrm{Cr}-3 \mathrm{Fe}-1.5 \mathrm{Ti}-1.5 \mathrm{Ce}$ alloy prepared at $28 \mathrm{~m} \mathrm{~s}^{-1}$, the wheel side is marked by arrow; c) rapidly solidified ribbon cross-section of Al-5.5Cr-3Fe$1.5 \mathrm{Ti}-3 \mathrm{Ce}$ alloy prepared at $28 \mathrm{~m} \mathrm{~s}^{-1}$, the wheel side is marked by arrow. 
Table 3. Thickness of homogeneous ultra rapidly quenched areas in the alloys

\begin{tabular}{lc}
\hline Alloy & Average width $(\mu \mathrm{m})$ \\
\hline Al-5.5Cr-3Fe-1.5Ti & $7.33 \pm 1.25$ \\
Al-5.5Cr-3Fe-1.5Ti-1.5Ce & $12.50 \pm 1.84$ \\
Al-5.5Cr-3Fe-1.5Ti-3Ce & $17.46 \pm 5.08$ \\
\hline
\end{tabular}

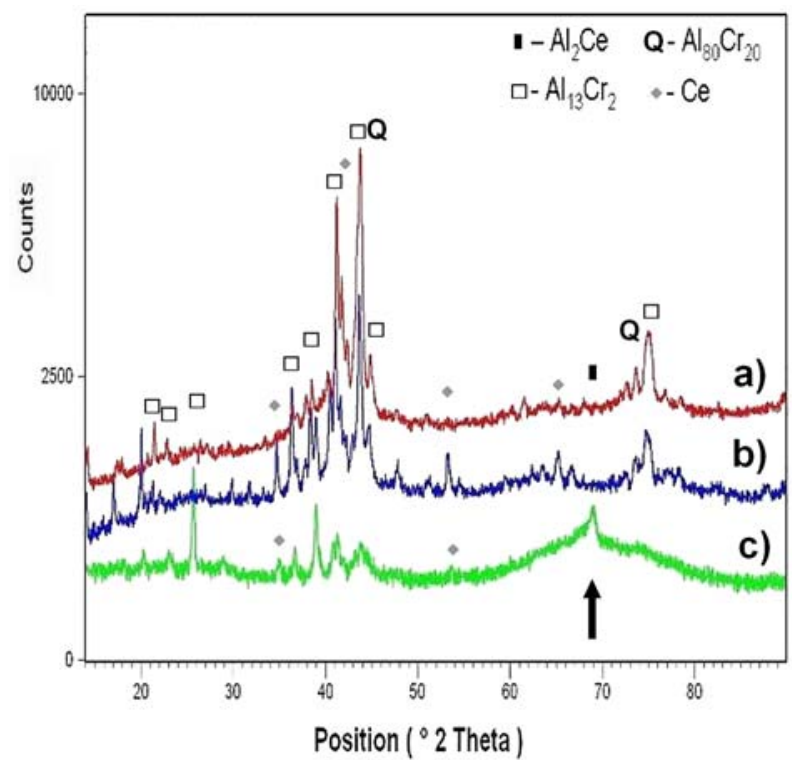

Fig. 8. XRD patterns of intermetallic phases extracted from ribbons prepared at $28 \mathrm{~m} \mathrm{~s}^{-1}$ : a) Al-5.5Cr-3Fe-1.5Ti, b) $\mathrm{Al}-5.5 \mathrm{Cr}-3 \mathrm{Fe}-1.5 \mathrm{Ti}-1.5 \mathrm{Ce}$ and c) $\mathrm{Al}-5.5 \mathrm{Cr}-3 \mathrm{Fe}-1.5 \mathrm{Ti}-$ $3 \mathrm{Ce}$. The patterns a) and b) are artificially shifted to higher intensities. The pattern c) exhibits amorphous area marked by an arrow.

$\mathrm{Al}$ have negative mixing enthalpy $\left(-38 \mathrm{~kJ} \mathrm{~mol}^{-1}[17]\right)$ and $\mathrm{Ce}$ atomic radius significantly exceeds radii of all other elements in the alloy [14].

XRD patterns of intermetallic phases extracted from ribbons with different Ce content prepared at $28 \mathrm{~m} \mathrm{~s}^{-1}$ are shown in Fig. 8. An XRD pattern of intermetallic phases extracted from the rapidly solidified alloy with the highest Ce content seems to exhibit amorphous phase. This amorphous phase probably results from a partial dissolution of $\mathrm{Al}$ from intermetallic particles, which means that in this case the dissolving solution is not selective and reacts not only with fcc-Al but also with intermetallics. In agreement with this idea, no amorphous phase is observed in the XRD pattern of rapidly solidified ribbon, see Fig. 9. The Al-5.5Cr-3Fe-1.5Ti-3Ce rapidly solidified ribbon contains similar equilibrium phases (fcc-Al and $\mathrm{Al}_{13} \mathrm{Cr}_{2}$ ) and the same decagonal quasicrystalline phase $\mathrm{Al}_{80} \mathrm{Cr}_{20}$ as the $\mathrm{Al}-5.5 \mathrm{Cr}-3 \mathrm{Fe}-1.5 \mathrm{Ti}$ alloy. In ad-

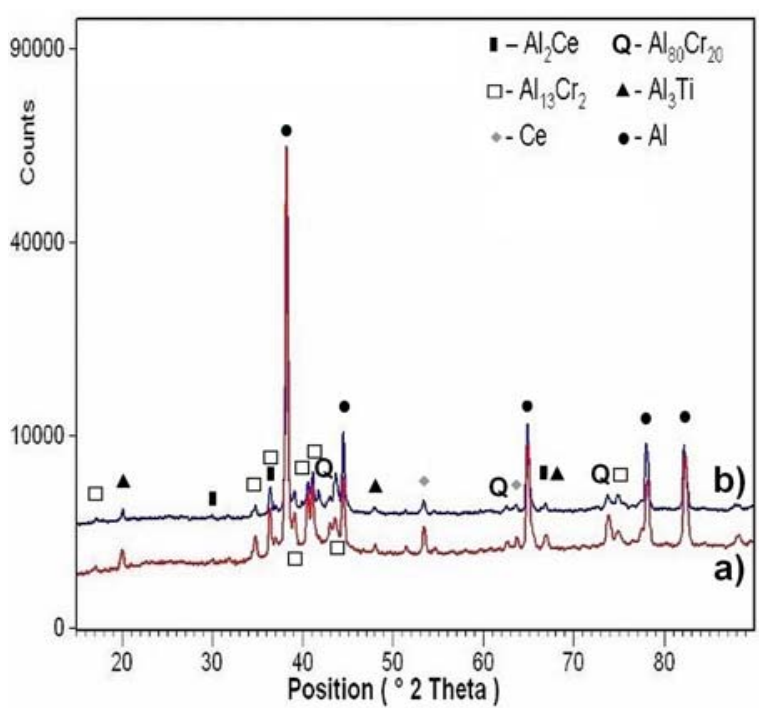

Fig. 9. XRD patterns of Al-5.5Cr-3Fe- $1.5 \mathrm{Ti}-3 \mathrm{Ce}$ ribbon prepared at $28 \mathrm{~m} \mathrm{~s}^{-1}$ : a) rapidly solidified, b) annealed for $100 \mathrm{~h}$ at $400^{\circ} \mathrm{C}$.

dition to them, there are also equilibrium phases $\mathrm{Al}_{3} \mathrm{Ti}$ and $\mathrm{CeAl}_{2}$ and a small amount of $\mathrm{Ce}$, which probably remains after the preparation of the alloy. Interestingly, $\mathrm{CeAl}_{2}$ phase was found among the intermetallic phases, although $\mathrm{Al}_{4} \mathrm{Ce}$ phase is generally reported in similar materials $[4,18,19]$.

In contrast to the $\mathrm{Al}-5.5 \mathrm{Cr}-3 \mathrm{Fe}-1.5 \mathrm{Ti}$ alloy, the $\mathrm{Al}-$ $-5.5 \mathrm{Cr}-3 \mathrm{Fe}-1.5 \mathrm{Ti}-3 \mathrm{Ce}$ alloy does not completely decompose during annealing at $400{ }^{\circ} \mathrm{C} / 100 \mathrm{~h}$, as shown in Fig. 9. These results suggest that the Ce addition stabilizes the quasicrystals. It was shown [16] that the addition of Ce into the $\mathrm{Al}$ matrix causes non-equilibrium segregation on grain boundaries for Ce atoms in $\mathrm{Al}$. More research will be needed; particularly TEM observation of rapidly solidified and annealed ribbons containing $\mathrm{Ce}$, to explain the mechanism of thermal stabilization of quasicrystals by Ce addition.

The thermal stability of alloys was studied by measuring the room temperature hardness after thermal treatment at $400^{\circ} \mathrm{C}$. As shown in Fig. 10, all alloys are sufficiently stable because their hardness does not reduce. The reason for the stabilization can be found in the very fine particles of the intermetallic phases.

\section{Conclusion}

Rapidly solidified Al-5.5Cr-3Fe-1.5Ti alloy, prepared by the melt spinning method, was composed of fcc- $\mathrm{Al}, \mathrm{Al}_{13} \mathrm{Cr}_{2}$ phase and quasicrystalline $\mathrm{Al}_{80}(\mathrm{Cr}$, $\mathrm{Fe})_{20}$. The amount of the quasicrystalline phase was dependent on the quenching rate used for the preparation of rapidly solidified ribbons. During annealing at $400^{\circ} \mathrm{C}$ the quasicrystalline phase decomposed form- 


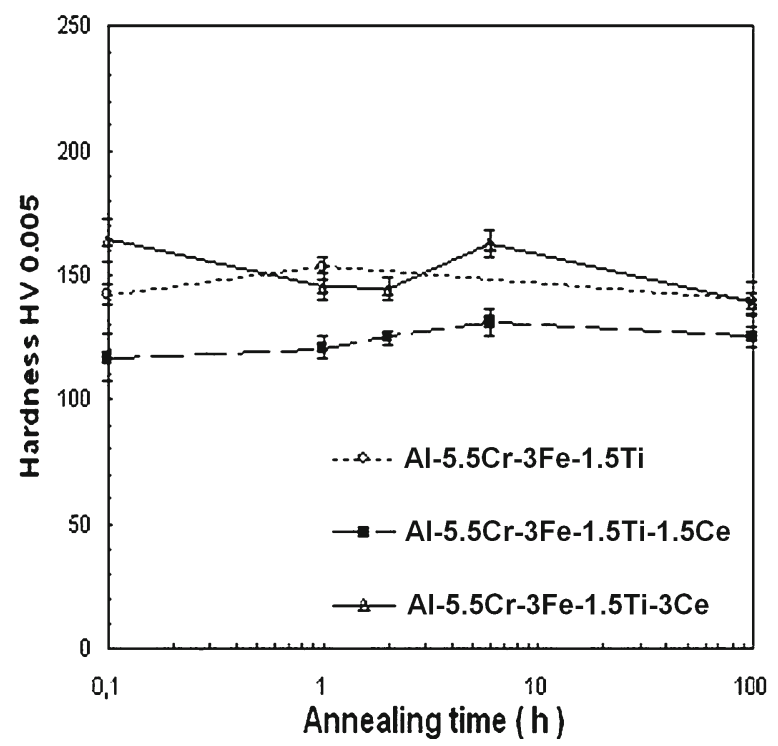

Fig. 10. Dependence of room temperature hardness on annealing time during annealing at $400^{\circ} \mathrm{C}$.

ing the $\mathrm{Al}_{13} \mathrm{Cr}_{2}$ phase. The addition of Ce slightly changed the phase composition and stabilized the quasicrystalline phase for elevated temperatures. All studied alloys exhibited good thermal stability - their hardness did not change even after annealing for $100 \mathrm{~h}$ at $400^{\circ} \mathrm{C}$.

\section{Acknowledgements}

Authors would like to thank to Dr. RNDr. Petr Bezdička, Ing. Jan Drahokoupil and RNDr. Jaroslav Maixner, CSc. for useful discussions about XRD.

The financial supports of the Czech Academy of Sciences (project no. KAN 300100801), of the Ministry of Education, Youth and Sports of the Czech Republic (project no. MSM6046137302) and of ICT Prague (internal grant project Preparation of Al-based alloys with elevated temperature stability) are gratefully acknowledged.

\section{References}

[1] INOUE, A.-KIMURA, H.: Nanostructured Materials, 11, 1999, p. 221.
[2] NAGAISHI, Y.-YAMASAKI, M.-KAWAMURA, Y.: Materials Science and Engineering A, 449-451, 2007, p. 794.

[3] KAWAMURA, Y.-INOUE, A.-TAKAGI, M.IMURA, T.: Materials Transactions JIM, 40, 1999, p. 392.

[4] ZHANG, C.-WU, Y.-CAI X.-ZHAO, F.ZHENG, S.-ZHOU, G.-WU, S.: Materials Science and Engineering A, 323, 2002, p. 226.

[5] MICHNA, S.-LUKÁČ, I.-OČENÁŠEK, V.-KOŘENY, R. -DRÁPALA, J.-SCHNEIDER, H.-MIŠKUFOVÁ, A.: Aluminium Materials and Technologies from A to Z. Prešov, Adin 2007.

[6] YANG, H.-WANG, J. Q.-LI, Y.: Journal of NonCrystalline Solids, 354, 2008, p. 3473.

[7] VOJTĚCH, D.-MICHALCOVÁ, A.-PILCH, J.ŚITTNER, P.-ŠERAK, J.-NOVÁK, P.: Journal of Alloys and Compounds, 475, 2009, p. 151.

[8] YAMASAKI, M.-NAGAISHI, Y.-KAWAMURA, Y.: Scripta Materialia, 56, 2007, p. 785.

[9] INOUE, A.-KIMURA, H.: Materials Science and Engineering A, 286, 2000, p. 1.

[10] WATANABE, M.-ITO, M.-KIMURA, H.-INOUE, A.-MASUMOTO, T.: Materials Science and Engineering A, 179/180, 1994, p. 659.

[11] SONG, K.-BIAN, X.-GUO, J.-WANG, S.-SUN, B.-LI, X.-WANG, C.- Journal of Alloys Compounds, 440, 2007, p. L8.

[12] BÁRTOVÁ, B.-VOJTĚCH, D.-VERNER, J.GEMPERLE, A.-STUDNIČKA, V.: Journal of Alloys Compounds, 387, 2005, p. 193.

[13] KIDO, O.-KURUMADA, M.-KAMITSUJI, K.TANIGAKI, T.-SATO, T.-KIMURA, Y.-SUZUKI, H.-SAITO, Y.-KAITO, C.: Physica E, 31, 2006, p. 169.

[14] http://www.en.wikipedia.org/wiki/Atomic_radius (7.7.2009)

[15] DU, Y.-CHANG, Y. A.-HUANG, B.-GONG, W.-JIN, Z.-XU, H.-YUAN, Z.-LIU, Y.-HE, Y.-XIE, F.-Y.: Materials Science and Engineering A, 363, 2003, p. 140.

[16] WEIPING, C.: Journal of Materials Science Letters, 16, 1997, p. 1824.

[17] SONG, K.-BIAN, X.-LV, X.-GUO, J.-LI, G.XIE, M.: Materials Science and Engineering A, 506, 2009, p. 87.

[18] WANG, S. H.-BIAN, X. F.: Journal of Alloys Compounds, 441, 2007, p. 135.

[19] NEIKOV, O. D.-MILMAN, Y. V.-SIRKO, A. I.SAMELJUK, A. V.-KRAJNIKOV, A.V.: Materials Science and Engineering A, 447, 2008, p. 80. 